\title{
Stepwise screening for diabetes identifies people with high but modifiable coronary heart disease risk. The ADDITION study
}

\author{
A. Sandbaek • S. J. Griffin • G. Rutten • M. Davies • \\ R. Stolk • K. Khunti • K. Borch-Johnsen • \\ N. J. Wareham • T. Lauritzen
}

Received: 24 October 2007 / Accepted: 25 March 2008 / Published online: 29 April 2008

(C) The Author(s) 2008

\begin{abstract}
Aims/hypothesis The Anglo-Danish-Dutch study of intensive treatment in people with screen-detected diabetes in primary care (ADDITION) is a pragmatic randomised controlled trial of the effectiveness of intensified multifactorial treatment on 5 year cardiovascular morbidity and mortality rates in people with screen-detected type 2 diabetes in the Netherlands, UK and Denmark. This paper describes the baseline characteristics of the study population, their estimated risk of coronary heart disease and the extent to which that risk is potentially modifiable.

Methods Stepwise screening strategies were performed using risk questionnaires and routine general practice data plus random blood glucose, $\mathrm{HbA}_{1 \mathrm{c}}$ and fasting blood glucose measurement. Diabetes was diagnosed using the 1999 World Health Organization criteria and estimated 10 year coronary heart disease risk was calculated using the UK Prospective Diabetes Study risk engine.

Results Between April 2001 and December 2006, 3,057 people with screen-detected diabetes were recruited to
\end{abstract}

A. Sandbaek $\cdot$ K. Borch-Johnsen · T. Lauritzen

Department of General Practice, Institute of Public Health,

University of Aarhus,

Aarhus, Denmark

\section{S. J. Griffin • N. J. Wareham $(\bowtie)$}

MRC Epidemiology Unit,

Institute of Metabolic Science,

Box 285, Addenbrooke's Hospital, Hills Road,

Cambridge CB2 0QQ, UK

e-mail: nick.wareham@mrc-epid.cam.ac.uk

G. Rutten

Julius Centre for Health Sciences and Primary Care,

University Medical Centre Utrecht,

Utrecht, the Netherlands the study (mean age 59.7 years, 58\% men) after a stepwise screening programme involving 76,308 people screened in 334 general practices in three countries. Their median estimated 10 year risk of coronary heart disease was $11 \%$ in women (interquartile range $7-16 \%$ ) and $21 \%(15-30 \%)$ in men. There were differences in the distribution of risk factors by country, linked to differences in approaches to screening and the extent to which risk factors had already been detected and treated. The mean $\mathrm{HbA}_{1 \mathrm{c}}$ at recruitment was 7.0\% (SD 1.6\%). Of the people recruited, $73 \%$ had a blood pressure $\geq 140 / 90$ and of these $58 \%$ were not on antihypertensive medication. Cholesterol levels were above $5.0 \mathrm{mmol} / 1$ in $70 \%$ of participants, $91 \%$ of whom were not being treated with lipid-lowering drugs.

Conclusions/interpretation People with type 2 diabetes detected by screening and included in the ADDITION study have a raised and potentially modifiable risk of CHD.

ClinicalTrials.gov ID no.: NCT 00237549.

M. Davies

Department of Cardiovascular Sciences, University of Leicester,

Leicester, UK

R. Stolk

Department of Epidemiology,

University Medical Centre Groningen,

Groningen, the Netherlands

K. Khunti

Department of Health Sciences, University of Leicester,

Leicester, UK

K. Borch-Johnsen

Steno Diabetes Centre,

Gentofte, Denmark 
Keywords Coronary heart disease · Diagnosis . General practice $\cdot$ Screening $\cdot$ Type 2 diabetes mellitus

\section{Abbreviations \\ ADDITION Anglo-Danish-Dutch study of intensive treatment in people with screen-detected diabetes in primary care \\ UKPDS UK Prospective Diabetes Study}

\section{Introduction}

People with type 2 diabetes mellitus are at increased risk of developing micro- and macrovascular complications and a substantial reduction in life expectancy [1]. The onset of this increased risk predates the point of clinical recognition by several years [2] such that at diagnosis approximately $50 \%$ of people have evidence of diabetes-related complications [3-8]. Given the high prevalence of undiagnosed diabetes [9-11] and the evidence that in people with clinically diagnosed diabetes the risk of complications can be effectively reduced by intensive treatment of hyperglycaemia [5-8] hypertension [12-14] and dyslipidaemia $[15,16]$, screening and earlier initiation of such treatment has been the subject of considerable debate [17-19]. However, critical uncertainties exist about the cost-effectiveness and potential adverse consequences of screening, and given this uncertainty, many international and national bodies have concluded that population-based screening should not be recommended without further evidence. A key uncertainty factor in assessing the balance between the costs and benefits of implementing policies for early detection of diabetes is the magnitude of cardiovascular risk reduction following early detection and intensive therapy [11]. Quantification of this risk reduction is the goal of the Anglo-Danish-Dutch study of intensive treatment in people with screen-detected diabetes in primary care (ADDITION), a randomised controlled trial of intensive multifactorial therapy in people with screen-detected diabetes in primary care. The aim of the analysis reported in this paper is to describe the baseline characteristics of the participants in the ADDITION study and in particular to quantify their estimated risk of CHD using the risk prediction equations developed in the UK Prospective Diabetes Study (UKPDS). We also describe the extent to which the estimated CHD risk in ADDITION study participants is potentially modifiable.

\section{Methods}

Study design The ADDITION study is a pragmatic randomised controlled trial of intensive multi-factorial treatment compared with standard care in people with screen-detected diabetes. The rationale and design of the study have been reported previously [20]. Recruitment to the study commenced in April 2001 and was completed in December 2006 by which time 3,057 people with screen-detected diabetes were recruited from four centres: one in Denmark, two in UK (Cambridge and Leicester) and one in the Netherlands. The primary endpoint for the 5 year follow-up in December 2009 will be a composite cardiovascular outcome comprised of cardiovascular mortality and morbidity (myocardial infarction, non-fatal stroke) revascularisations and amputations.

Screening procedures In order to identify potential recruits to this study, ADDITION undertook a programme of population-based stepwise screening among people aged 40 to 69 years who were not known to have diabetes. Individuals at high risk of diabetes were initially identified using self-administered questionnaires in Denmark [21] and the Netherlands $[22,23]$ or by automated search of computerised general practice records in the UK [24]. Those at high risk were asked to contact their physician (Denmark), attend a community-based screening clinic (the Netherlands) or were invited by letter to attend their local general practice (Cambridge) or a screening clinic (Leicester). A sequential process of screening using random glucose measurements and $\mathrm{HbA}_{1 \mathrm{c}}$, followed by fasting glucose and OGTT as diagnostic tests was undertaken. In the Leicester centre, all people at high risk were invited directly for OGTT without the intermediate testing steps. Participants were diagnosed with diabetes according to the WHO criteria [25] using the requirement for confirmatory tests on separate occasions.

Biochemical assessment Whole-blood glucose was analysed by near-patient testing using a glucose analyser (HemoCue, Angelholm, Sweden). Calibration stability was checked on a daily basis using control cuvettes. All machines were registered with the HemoCue quality assurance scheme and were externally calibrated at the start of screening and subsequently recalibrated at regular intervals. $\mathrm{HbA}_{1 \mathrm{c}}$ was analysed in venous samples in five local laboratories. The laboratories in Denmark (at Steno Diabetes Centre, Gentofte, and Aarhus University Hospital, Tage Hansensgade, Aarhus) and Cambridge (Department of Clinical Biochemistry at Addenbrookes Hospital, Cambridge) used ion-exchange high-performance liquid chromatography on Tosoh machines (Tosoh Bioscience, Redditch, UK). The laboratory in the Leicester centre (Leicester Royal Infirmary) used the Biorad Variant II system (Bio-Rad Laboratories, Hemel Hempstead, UK) and that in the Netherlands (SHL Center for Diagnostic Support in Primary Care, Etten-Leur, the Netherlands) used a Menarini 8140 machine (Menarini, 
Florence, Italy). A validation study comparing the different laboratories demonstrated no noticeable systematic differences $(<0.2 \%)$ in the $\mathrm{HbA}_{1 \mathrm{c}}$ range of 3 to $11 \%$. The repeatability and reproducibility were within the range 0.1 to $0.5 \%$ in all laboratories. Fasting serum samples were analysed in the same local laboratories for cholesterol, HDL-cholesterol and triacylglycerol using standard enzymatic methods. LDL-cholesterol was calculated using the Friedewald formula [26]. Plasma creatinine concentration was analysed with kinetic colorimetric methods. Urinary albumin was measured on spot urine by the immunotubidimetric method and urinary creatinine by the colorimetric method. The urinary albumin: creatinine ratio was used to define microalbuminuria as $\geq 2.5 \mathrm{mg} / \mathrm{mmol}$ in women and $\geq 3.5 \mathrm{mg} / \mathrm{mmol}$ in men.

Clinical measures Anthropometric measurements were undertaken at baseline by trained staff following standard operating procedures with height being measured to the nearest $0.1 \mathrm{~cm}$ using a fixed rigid stadiometer and weight in light indoor clothing measured to the nearest $0.1 \mathrm{~kg}$ with a Seca scale. Body mass index $\left(\mathrm{kg} / \mathrm{m}^{2}\right)$ was defined as weight in kilograms divided by height in metres squared. Waist circumference was measured at the mid-point between the lower costal margin and the level of the anterior superior iliac crest to the nearest $0.1 \mathrm{~cm}$. Blood pressure was measured using an Omron M4 blood pressure recorder (Omron Healthcare, Milton Keynes, UK) with the participant in a sitting position.

Questionnaires Self-completed questionnaires were used to assess baseline smoking status, alcohol consumption, occupational status, ethnicity and self-reported medication. Where needed, instruments were translated and backtranslated and the accuracy of translation verified using established methods [27].

UKPDS risk engine The estimated absolute 10 year risk of CHD was calculated using the previously published UKPDS risk engine [28]. The risk was only estimated for those participants with complete data on all the composite risk factors required for the calculation, i.e. age, sex, ethnicity, smoking status, $\mathrm{HbA}_{1 \mathrm{c}}$, systolic blood pressure, total cholesterol and HDL-cholesterol, and duration of diabetes, which for this population was by definition 0 years since all the participants had screen-detected diabetes.

Ethics The study was approved by the local scientific ethics committees in the specific countries and counties and was conducted in accordance with the principles of the 1996 Helsinki Declaration. All participants provided informed consent.
Data-handling and statistics The comparison of the baseline characteristics of the study participants by group was undertaken using Student's $t$ tests for continuously distributed data and $\chi^{2}$ tests for categorical variables. The KruskalWallis test was used where data were not normally distributed or unequal variances were present. We used an imputation method to estimate the impact of missing data for the UKPDS risk score on our results. Missing continuous data such as $\mathrm{HbA}_{1 \mathrm{c}}$, systolic blood pressure, total cholesterol and HDLcholesterol were imputed using the best-subset regressions procedure [29]. Missing data for the categorical variables (ethnicity and smoking status) were imputed using logistic regression imputation. Where the predicted value was $<0.5$ it was coded as 0 and where it was $\geq 0.5$ it was coded as 1 . No sensitivity analyses of the imputation procedure were done. All analyses were undertaken using Intercooled STATA 9.0 (StataCorp LP, College Station, TX, USA).

\section{Results}

Recruitment By the end of the screening phase of the ADDITION study, 334 general practices (182 in Denmark, 49 in Cambridge, 24 in Leicester and 79 in the Netherlands) had screened 76,308 people $(28,031$ in Denmark, 24,654 in Cambridge, 5,740 in Leicester and 17,883 in the Netherlands). In total, 3,233 individuals with screen-detected diabetes were identified and a total of 3,057 individuals (1,533 in Denmark, 867 in Cambridge, 159 in Leicester and 498 in the Netherlands) were recruited to the ADDITION study. There were no significant differences in the characteristics of the 3,057 participants recruited to the trial compared with the 176 patients with screen-detected diabetes who were eligible but chose not to participate.

Baseline characteristics The baseline characteristics of the participants recruited to the trial including the risk factors for CHD are shown in Table 1. Across the centres significant differences were seen in the demographic characteristics of the participants, largely by virtue of differences in the underlying populations and the approach to screening. The Leicester population differed from the other three centres by having the youngest population (mean age $=57.2$ years compared with 59.9 years in the other three groups, $p<0.001$ ), the highest proportion of participants who were non-white (41.3 compared with $3.9 \%$ in the other groups, $p<0.001$ ) and the highest proportion of people who were not employed (7.7 compared with $2.2 \%$ in the other centres, $p<0.01$ ). The Danish population had the highest proportion of smokers (35\% compared with $26 \%$ in the Netherlands, $18 \%$ in Cambridge and $16 \%$ in Leicester, $p<0.001$ ) and also had the highest intake of alcohol units per week. The mean 
Table 1 Baseline characteristics of the 3,057 participants (1,771 men, 1,286 women) with screen-detected diabetes recruited to the ADDITION study (2001-2006)

\begin{tabular}{|c|c|c|c|c|}
\hline & $n$ with complete information & Total & Men & Women \\
\hline Age at diagnosis (years) & 3,057 & $59.7 \pm 6.8$ & $59.2 \pm 7.0$ & $60.4 \pm 6.6^{* *}$ \\
\hline Non-white $(\%)$ & 2,941 & 5.3 & 5.0 & 5.8 \\
\hline Alcohol consumption (units/week) & 2,675 & $4(0-162)$ & $8(0-162)$ & $2(0-115)$ \\
\hline Current smokers $(\%)$ & 2,996 & 27 & 29 & $25 * *$ \\
\hline Unemployed (\%) & 2,955 & 2.5 & 2.8 & 2.1 \\
\hline Already on antihypertensive treatment (\%) & 2,803 & 41 & 37 & $47^{* *}$ \\
\hline Already on lipid-lowering treatment $(\%)$ & 2,803 & 14 & 15 & $13 *$ \\
\hline $\mathrm{HbA}_{1 \mathrm{c}}(\%)$ & 2,888 & $7.0 \pm 1.6$ & $7.1 \pm 1.7$ & $6.9 \pm 1.4^{*}$ \\
\hline Systolic BP (mmHg) & 2,961 & $151 \pm 23$ & $152 \pm 22$ & $151 \pm 23$ \\
\hline Diastolic BP (mmHg) & 2,962 & $87 \pm 12$ & $88 \pm 12$ & $86 \pm 11 * *$ \\
\hline BMI $\left(\mathrm{kg} / \mathrm{m}^{2}\right)$ & 2,960 & $31.6 \pm 5.6$ & $31.0 \pm 5.0$ & $32.3 \pm 6.2^{* *}$ \\
\hline Waist (cm) & 2,959 & $107 \pm 13$ & $109 \pm 13$ & $103 \pm 14^{* *}$ \\
\hline Total cholesterol $(\mathrm{mmol} / \mathrm{l})$ & 2,892 & $5.6 \pm 1.1$ & $5.4 \pm 1.1$ & $5.7 \pm 1.1 * *$ \\
\hline Total triacylglycerol (mmol/l) & 2,873 & $2.0 \pm 1.5$ & $2.1 \pm 1.7$ & $1.9 \pm 1.1^{* *}$ \\
\hline HDL-cholesterol (mmol/l) & 2,856 & $1.3 \pm 0.4$ & $1.2 \pm 0.4$ & $1.4 \pm 0.4^{* *}$ \\
\hline LDL-cholesterol (mmol/l) & 2,762 & $3.4 \pm 1.0$ & $3.3 \pm 1.0$ & $3.5 \pm 1.0 * *$ \\
\hline Plasma creatinine $(\mu \mathrm{mol} / \mathrm{l})$ & 2,830 & $84 \pm 18$ & $90 \pm 17$ & $75 \pm 15^{* *}$ \\
\hline With microalbuminuria $(\%)^{\mathrm{a}}$ & 2,757 & 18.4 & 17.6 & 19.5 \\
\hline
\end{tabular}

Data shown are mean $\pm \mathrm{SD}$, median (range) or percentages

${ }^{\mathrm{a}}$ Urinary albumin:creatinine ratio $>2.5$ (women), $>3.5$ (men)

$* p<0.05$ vs men

$* * p<0.001$ vs men

$\mathrm{HbA}_{1 \mathrm{c}}$ was lower in the Danish population $(6.8 \%)$ than in the other three centres (overall mean $7.3 \%, p<0.001$ ).

Anti-hypertensive, lipid-lowering and antiplatelet therapy In the total study population $73 \%$ of the participants had a blood pressure greater than $140 / 90 \mathrm{mmHg}$ and of these $58 \%$ had not been prescribed antihypertensive medication. Therefore, overall $42 \%$ of the cohort was hypertensive but not being treated. Even in the subpopulation of people already receiving antihypertensive therapy (Table 2) there was evident room for enhancement of blood pressure lowering, since the mean blood pressure level in this

Table 2 Baseline characteristics of participants with screen-detected diabetes recruited to the ADDITION study (2001-2006), stratified by antihypertensive therapy status

\begin{tabular}{lll}
\hline & $\begin{array}{l}\text { Already on } \\
\text { antihypertensive therapy }\end{array}$ & $\begin{array}{l}\text { No antihypertensive } \\
\text { therapy }\end{array}$ \\
\hline$n(\%)$ & $1,159(41)$ & $1,644(59)$ \\
Age (years) & $60.9 \pm 6.5$ & $59.0 \pm 7.0^{* *}$ \\
BMI $\left(\mathrm{kg} / \mathrm{m}^{2}\right)$ & $32.4 \pm 5.7$ & $31.0 \pm 5.4^{* *}$ \\
Systolic BP & $151 \pm 22$ & $152 \pm 23$ \\
$(\mathrm{mmHg})$ & & $88 \pm 12^{*}$ \\
$\begin{array}{c}\text { Diastolic BP } \\
(\mathrm{mmHg})\end{array}$ & $86 \pm 12$ & \\
\hline
\end{tabular}

Data shown are mean $\pm \mathrm{SD}$, unless otherwise indicated $* p<0.05$ vs participants on antihypertensive therapy $* * p<0.001$ vs participants on antihypertensive therapy supposedly treated group was $151 / 86 \mathrm{mmHg}$. Indeed the blood pressure levels in the population receiving therapy were only marginally lower than those in the untreated group. In this group, $67 \%$ of people did not meet the treatment goal of a blood pressure of 140/90 showing the potential for intensified therapy or for behavioural modifications to enhance treatment adherence. Similarly, 70\% of the cohort had a cholesterol level above $5.0 \mathrm{mmol} / \mathrm{l}$. More women $(75 \%)$ than men $(65 \%, p<0.001)$ were hypercholesterolaemic. Nearly all of these people with high cholesterol levels $(91 \%)$ were not being treated with lipidlowering pharmaceuticals. Overall $64 \%$ of the participants in the ADDITION trial had a total cholesterol level above $5 \mathrm{mmol} / \mathrm{l}$ at baseline but were not being treated. Among the people who were receiving lipid-lowering therapy (Table 3), there was evidence, as with blood pressure, that scope for intensifying therapy or enhancing adherence existed, since the mean cholesterol level in those receiving treatment was $4.9 \mathrm{mmol} / \mathrm{l}$ with a mean LDL-cholesterol of $2.8 \mathrm{mmol} / \mathrm{l}$. Of these individuals, $41 \%$ were not meeting the treatment goal of a cholesterol level lower than $5 \mathrm{mmol} / \mathrm{l}$. Of the total population $15 \%$ had aspirin treatment at inclusion.

The two UK centres had the highest proportion of people already on antihypertensive and lipid-lowering treatment at baseline. In Cambridge and Leicester 49 and $58 \%$ of the participants respectively were already on antihypertensive therapy compared with $32 \%$ in Denmark and $37 \%$ in the Netherlands $(p<0.001)$. The mean systolic BP was lower in 
Table 3 Baseline characteristics of participants with screen-detected diabetes recruited to the ADDITION study (2001-2006), stratified by lipid-lowering therapy status

\begin{tabular}{lll}
\hline & $\begin{array}{l}\text { Already on lipid- } \\
\text { lowering therapy }\end{array}$ & $\begin{array}{l}\text { No lipid-lowering } \\
\text { therapy }\end{array}$ \\
\hline$n(\%)$ & $405(14)$ & $2,398(86)$ \\
Age (years) & $61.4 \pm 6.0$ & $59.5 \pm 6.9^{* *}$ \\
BMI $\left(\mathrm{kg} / \mathrm{m}^{2}\right)$ & $31.3 \pm 5.2$ & $31.7 \pm 5.2$ \\
$\begin{array}{l}\text { Total cholesterol } \\
(\mathrm{mmol} / \mathrm{l})\end{array}$ & $4.9 \pm 1.0$ & $5.6 \pm 1.1^{* *}$ \\
$\begin{array}{l}\text { Total triacylglycerol } \\
(\mathrm{mmol} / \mathrm{l})\end{array}$ & $2.2 \pm 2.0$ & $2.0 \pm 1.4^{*}$ \\
$\begin{array}{l}\text { HDL-cholesterol } \\
(\mathrm{mmol} / \mathrm{l})\end{array}$ & $1.2 \pm 0.4$ & $1.3 \pm 0.4^{* *}$ \\
$\begin{array}{l}\text { LDL-cholesterol } \\
(\mathrm{mmol} / \mathrm{l})\end{array}$ & $2.8 \pm 0.9$ & $3.5 \pm 1.0^{* *}$ \\
\hline
\end{tabular}

Data shown are mean $\pm \mathrm{SD}$, unless otherwise indicated $* p<0.05$ vs participants on lipid lowering therapy

$* * p<0.001$ vs participants on lipid lowering therapy

the UK populations (145 $\mathrm{mmHg}$ ) and in Denmark (151 $\mathrm{mmHg}$ ) than among the Dutch $(165 \mathrm{mmHg}, p<0.001)$. The mean diastolic blood pressure was significantly lower in the Cambridge population than in the other populations (83 $\mathrm{mmHg}$ compared with $89 \mathrm{mmHg}$ in all other centres, $p<0.001)$. A similar pattern was seen for lipid-lowering therapy, which was being prescribed to 26 and $21 \%$ of the participants in Cambridge and Leicester respectively, compared with $9 \%$ in Denmark and $15 \%$ in the Netherlands $(p<0.001)$. The mean total cholesterol concentration was lowest in the Cambridge population compared with the other centres $(5.3 \mathrm{mmol} / \mathrm{l}$ vs $5.6 \mathrm{mmol} / \mathrm{l}$ in all other centres, $p<0.001)$.

CHD risk Table 4 shows the estimated absolute 10 year CHD risk by age-group and sex. In the whole group, the median 10 year risk was 16\% (interquartile range 10-25\%). The estimated risk for CHD was higher for men (median value $=21 \%$; interquartile range: $15-30$ ) than for women $(11 \% ; 7-16 ; p<0.001)$, and the oldest age group had a significant higher risk than the younger groups $(p<0.001)$. We also observed minor differences in estimated risk between countries, with the Dutch population having the highest risk of developing $\mathrm{CHD}$ in the older age groups $(p<0.001)$. These high levels of estimated risk, together with the high mean level of baseline $\mathrm{HbA}_{1 \mathrm{c}}$ plus the untreated hyperlipidaemia and hypertension, provide clear justification for examining the impact of intensified multifactorial therapy on this potentially modifiable risk.

Missing data As the UKPDS CHD risk score uses multiple factors, it is susceptible to missing data since all variables must be present for each individual for risk to be calculated. A full dataset was available for $83 \%$ of the total population. However, we investigated the effect of missing data on the overall median CHD risk by imputing missing variables in the remaining $17 \%$ of the population. As the results in Table 4 demonstrate, the median CHD risk estimates were unchanged when we included the values calculated using imputation. This suggests that the results are not biased by any specific characteristics of the individuals for whom some data were missing.

\section{Discussion}

This analysis of the baseline data from the recruited participants in the multi-national ADDITION trial demonstrates that stepwise screening for diabetes in general practice identifies people with type 2 diabetes whose estimated 10 year CHD risk is high. In addition to their untreated hyperglycaemia, the majority of the people with demonstrable hypertension or hypercholesterolaemia were not receiving treatment or were not being treated sufficiently at baseline, suggesting that the elevated risk may be modifiable through intensified lifestyle and pharmacological therapy. In this trial, participants were randomised at the general practice level to standard care or an intensified approach geared to reducing cardiovascular risk. The 5 year follow-up of the trial participants in 2009 will show

Table 4 Median estimated 10 year absolute CHD risk calculated from the UKPDS risk engine at baseline in the ADDITION study participants (2001-2006), stratified by age and sex

\begin{tabular}{lrlcrr}
\hline Age group & \multicolumn{1}{c}{ Men } & Women & \multicolumn{1}{c}{ Total } & Total including imputed values $^{\text {a }}$ \\
\hline $40-49$ years & 216 & $12(8-15)$ & $5(3-7)$ & $9(5-14)$ & $9(6-13)$ \\
$50-59$ years & 930 & $18(13-24)$ & $8(6-11)$ & $14(9-20)$ & $14(9-20)$ \\
$60-69$ years & 1,398 & $26(19-34)$ & $13(10-18)$ & $19(13-28)$ & $19(13-28)$ \\
Total population & 2,544 & $21(15-30)$ & $11(7-16)$ & $16(10-25)$ & $16(10-24)$ \\
\hline
\end{tabular}

Data are \% (interquartile range), unless otherwise indicated. UKPDS risk can only be estimated in cases with complete data for all included variables

${ }^{\text {a }}$ Imputed values used when data were missing 
whether this approach to intervention will realise the potential for benefit on cardiovascular outcomes that the present analysis demonstrates.

Strengths and weaknesses of the study This study is large, involving the screening of 76,308 people in 334 general practices in order to find the 3,057 people with screendetected diabetes who were randomised to different approaches to care. A key element of the ADDITION trial design is that the intervention is delivered in primary care. The trial is a pragmatic evaluation of the magnitude of the costs and benefits of screening and intensified treatment in this real-world setting. This design has the advantage that one can generalise from the results of the trial to the expected outcome if and when the approach is more widely adopted. The disadvantage is that it is much more difficult from a practical perspective to undertake a trial embedded within everyday primary care practice than it is in a specialist research organisation. In the trial, a total of 334 general practices participated and although reminder systems were established to ensure that datasets were as complete as possible, there is a higher degree of missing data than would be present if the trial had been conducted in a more controlled environment.

Comparison with other studies The level of CHD risk estimated by the UKPDS risk engine in ADDITION trial participants who had been detected by a stepwise process of diabetes screening is comparable with that of diabetic patients of a similar age who have been diagnosed conventionally in routine clinical practice. In the analysis by Song and Brown of CHD risk estimation in 700 British patients with prevalent type 2 diabetes (mean age 59.8 years), the mean (SD) 10 year CHD risk in men was $24.9 \%$ (SD 13.2), whereas it was $16.5 \%$ (SD 9.4) in women [30]. Although the risk estimator ranks risk well, it may result in an underestimation of true risk. In a comparison of risk estimated by the UKPDS risk engine or the Framingham risk score compared with true risk, Guzder and colleagues demonstrated that the Framingham risk score underestimated coronary events in a population of people with type 2 diabetes by $32 \%$. At $13 \%$, the degree of underestimation by the UKPDS risk engine was lower [31]. As with all other risk calculators, the computation of risk for CHD by the UKPDS risk engine is heavily influenced by age and sex, since these are dominant factors that determine absolute risk levels. Thus in our study, by definition, estimated risk is higher in men and in the older age groups. Compared with the cohort of patients in the UKPDS study [4], the participants recruited to the ADDITION study were older, more obese, more hypertensive and had higher levels of serum cholesterol.
Similar differences also exist between the ADDITION study cohort and previous populations of people with screen-detected type 2 diabetes. Overall, ADDITION study participants are older, more obese and more hypertensive than people with prevalent but undiagnosed diabetes in the Ely [10] and Inter99 [9] studies. These differences between our participants and previous studies of prevalent and previously undiagnosed diabetes may be connected (1) with our requirement for confirmation of the biochemical diagnosis of diabetes on a different day, which was not a characteristic of some previous epidemiological studies, or (2) with the screening strategy employed by us, which used risk scores that predict prevalent but undiagnosed diabetes. Factors including age, BMI and presence of known hypertension are part of these risk scores. Thus, through their use as part of a process of stepwise screening, we may have combined screening for diabetes with the selection of individuals who are at higher cardiovascular risk. The only subpopulation in the ADDITION study in whom universal screening rather than a stepwise approach was used was that of the Leicester centre. As $40 \%$ of the recruited people with diabetes in Leicester were non-white, this approach is still likely to lead to the selection of a population at higher CHD risk [32]. We demonstrated between-country differences in the distribution of metabolic risk factors, which were due in part to variations in approaches to screening, variations in the prevalence of lifestyle behaviours (e.g. cigarette smoking), and differences in the extent to which risk factors such as blood pressure and lipids had already been detected and adequately treated.

Interpretation of our findings A key criterion that determines whether a screening programme for any particular condition should be considered is the availability of evidence showing that earlier detection and treatment is associated with improved outcomes. In the context of diabetes, if people whose disease was detected by screening were already receiving intensive treatment for CHD risk factors apart from hyperglycaemia, diagnosis of their diabetes should be unlikely to have a major impact on CHD risk. Thus the observation made in this study that people with screen-detected diabetes are at high CHD risk and that this risk is potentially modifiable by intensification of treatment could have a potentially critical impact. The scope for intervention is considerable, since in addition to untreated or insufficiently treated hyperglycaemia, hypertension and hypercholesterolaemia, nearly one third of the cohort were current smokers and almost all were overweight, high-lighting the potential for lifestyle intervention in addition to intensified pharmacological therapy. The task of determining whether such intensification of treatment is possible in primary care and whether it will have the 
expected impact on reducing cardiovascular events is a key goal of the 5 year follow-up of the ADDITION trial, which will be complete in 2009 .

Acknowledgements The ADDITION study in Denmark was supported by the National Health Services in the counties of Copenhagen, Aarhus, Ringkøbing, Ribe and South Jutland, together with the Danish Research Foundation for General Practice, Danish Centre for Evaluation and Health Technology Assessment, the diabetes fund of the National Board of Health, the Danish Medical Research Council, the Aarhus University Research Foundation and the Novo Nordisk Foundation. The study received unrestricted grants from Novo Nordisk, Novo Nordisk Scandinavia, Astra Denmark, Pfizer Denmark, GlaxoSmithKline Pharma Denmark, Servier Denmark and HemoCue Denmark.

In the UK, the ADDITION study at the Cambridge Centre was supported by the Wellcome Trust, the Medical Research Council, the National Health Service Research and Development Directorate, and by an unrestricted grant from Novo Nordisk UK. The Leicester Centre was supported by the Department of Health and an unrestricted grant from Servier UK.

In the Netherlands, the ADDITION Study was funded by unrestricted grants from Novo Nordisk Netherlands, GlaxoSmithKline Netherlands and Merck Netherlands.

Duality of interest The authors declare that, apart from the funding described above, there is no duality of interest associated with this manuscript.

Open Access This article is distributed under the terms of the Creative Commons Attribution Noncommercial License which permits any noncommercial use, distribution, and reproduction in any medium, provided the original author(s) and source are credited.

\section{References}

1. Laakso M, Lehto S (1997) Epidemiology of macrovascular disease in diabetes. Diabetes Rev 5:294-315

2. Harris MI, Klein R, Welborn TA, Knuiman MW (1992) Onset of NIDDM occurs at least 4-7 yr before clinical diagnosis. Diabetes Care 15:815-819

3. Spijkerman AM, Adriaanse MC, Dekker JM et al (2002) Diabetic patients detected by population-based stepwise screening already have a diabetic cardiovascular risk profile. Diabetes Care 25: 1784-1789

4. UK Prospective Diabetes Study 6 (1990) Complications in newly diagnosed type 2 diabetic patients and their association with different clinical and biochemical risk factors. Diabetes Res 13:1-11

5. UK Prospective Diabetes Study (UKPDS) (1991) VIII. Study design, progress and performance. Diabetologia 34:877-890

6. UK Prospective Diabetes Study (UKPDS) Group (1998) Intensive blood-glucose control with sulphonylureas or insulin compared with conventional treatment and risk of complications in patients with type 2 diabetes (UKPDS 33). Lancet 352:837-853

7. Guillausseau PJ, Massin P, Charles MA et al (1998) Glycaemic control and development of retinopathy in type 2 diabetes mellitus: a longitudinal study. Diabet Med 15:151-155

8. Coutinho M, Gerstein HC, Wang Y, Yusuf S (1999) The relationship between glucose and incident cardiovascular events. A metaregression analysis of published data from 20 studies of 95,783 individuals followed for 12.4 years. Diabetes Care 22:233-240
9. Glumer C, Jorgensen T, Borch-Johnsen K (2003) Prevalences of diabetes and impaired glucose regulation in a Danish population: the Inter99 Study. Diabetes Care 26:2335-2340

10. Williams DR, Wareham NJ, Brown DC et al (1995) Undiagnosed glucose intolerance in the community: the Isle of Ely Diabetes Project. Diabet Med 12:30-35

11. Glumer C, Yugun M, Griffin S et al (2006) What determines the costeffectiveness of diabetes screening? Diabetologia 49:1536-1544

12. Hansson L, Zanchetti A, Carruthers SG et al (1998) Effects of intensive blood-pressure lowering and low-dose aspirin in patients with hypertension: principal results of the Hypertension Optimal Treatment (HOT) randomised trial. HOT Study Group. Lancet 351:1755-1762

13. UK Prospective Diabetes Study Group (1998) Tight blood pressure control and risk of macrovascular and microvascular complications in type 2 diabetes: UKPDS 38. BMJ 317:703713

14. Lindholm LH, Ibsen H, Dahlof B et al (2002) Cardiovascular morbidity and mortality in patients with diabetes in the Losartan Intervention For Endpoint Reduction in Hypertension Study (LIFE): a randomised trial against atenolol. Lancet 359:10041010

15. Pyorala K, Pedersen TR, Kjekshus J, Faergeman O, Olsson AG, Thorgeirsson G (1997) Cholesterol lowering with simvastatin improves prognosis of diabetic patients with coronary heart disease. A subgroup analysis of the Scandinavian Simvastatin Survival Study (4S). Diabetes Care 20:614-620

16. Collins R, Armitage J, Parish S, Sleigh P, Peto R (2003) MRC/ BHF Heart Protection Study of cholesterol-lowering with simvastatin in 5963 people with diabetes: a randomised placebocontrolled trial. Lancet 361:2005-2016

17. Wareham NJ, Griffin SJ (2001) Should we screen for type 2 diabetes? Evaluation against national screening committee criteria. BMJ 322:986-988

18. Borch-Johnsen K, Lauritzen T, Glumer C, Sandbaek A (2003) Screening for type 2 diabetes-should it be now? Diabet Med $20: 175-181$

19. Sandbaek A, Lauritzen T, Borch-Johnsen K, Mai K, Christiansen JS (2005) The comparison of venous plasma glucose and whole blood capillary glucose in diagnoses of type 2 diabetes: a population-based screening study. Diabet Med 22:1173-1177

20. Lauritzen T, Griffin S, Borch-Johnsen $\mathrm{K}$, Wareham NJ, Wolffenbuttel BH, Rutten G (2000) The ADDITION study: proposed trial of the cost-effectiveness of an intensive multifactorial intervention on morbidity and mortality among people with type 2 diabetes detected by screening. Int J Obes Relat Metab Disord 24(Suppl 3):S6-S11

21. Glumer C, Carstensen B, Sandbaek A, Lauritzen T, Jorgensen T, Borch-Johnsen K (2004) A Danish diabetes risk score for targeted screening: the Inter99 Study. Diabetes Care 27:727-733

22. Ruige JB, de Neeling JN, Kostense PJ, Bouter LM, Heine RJ (1997) Performance of an NIDDM screening questionnaire based on symptoms and risk factors. Diabetes Care 20:491-496

23. Janssen PG, Gorter KJ, Stolk RP, Rutten GE (2007) Low yield of population-based screening for type 2 diabetes in the Netherlands. The ADDITION Netherlands Study. Fam Pract 24:555-561

24. Griffin SJ, Little PS, Hales CN, Kinmonth AL, Wareham NJ (2000) Diabetes risk score: towards earlier detection of type 2 diabetes in general practice. Diabetes Metab Res Rev 16:164-171

25. Alberti KG, Zimmet PZ (1999) Definition, diagnosis and classification of diabetes mellitus and its complications. Part 1: diagnosis and classification of diabetes mellitus. WHO, Geneva

26. Friedewald WT, Levy RI, Fredrickson DS (1972) Estimation of the concentration of low-density lipoprotein cholesterol in plasma, without use of the preparative ultracentrifuge. Clin Chem 18:499-502 
27. Guillemin F, Bombardier C, Beaton D (1993) Cross-cultural adaptation of health-related quality of life measures: literature review and proposed guidelines. J Clin Epidemiol 46:14171432

28. Stevens RJ, Kothari V, Adler AI, Stratton IM (2001) The UKPDS risk engine: a model for the risk of coronary heart disease in type II diabetes (UKPDS 56). Clin Sci 101:671-679

29. Little RJA, Rubin DB (2002) Statistical analysis with missing data, 2nd edn. Wiley, New York

30. Song SH, Brown PM (2004) Coronary heart disease risk assessment in diabetes mellitus: comparison of UKPDS risk engine with Framingham risk assessment function and its clinical implications. Diabet Med 21:238-245

31. Guzder RN, Gatling W, Mullee MA, Mehta RL, Byrne CD (2005) Prognostic value of the Framingham cardiovascular risk equation and the UKPDS risk engine for coronary heart disease in newly diagnosed type 2 diabetes: results from a United Kingdom study. Diabet Med 22:554-562

32. Bhopal R, Unwin N, White M et al (1999) Heterogeneity of coronary heart disease risk factors in Indian, Pakistani, Bangladeshi and European origin populations: cross sectional study. BMJ 319:215-220 